\title{
Emergency Table Stop Device
}

National Cancer Institute

\section{Source}

National Cancer Institute. Emergency Table Stop Device. NCI Thesaurus. Code C50309.

A mechanism designed to quickly halt the movement of a feed table. 